\title{
A Multicommuted Flow System for Spectrophotometric Determination of Formaldehyde in Mushroom
}

\author{
Gabriel F. Pinto, ${ }^{a}$ Diogo L. Rocha, ${ }^{b}$ Eduardo M. Richter, ${ }^{a}$ Rodrigo A. A. Muñoz ${ }^{* a}$ and \\ Sidnei G. da Silva*,a \\ anstituto de Química, Universidade Federal de Uberlândia, 38400-902 Uberlândia-MG, Brazil \\ ${ }^{b}$ Centro de Ciências Naturais e Humanas, Universidade Federal do ABC, 09210-580 Santo André-SP, Brazil
}

\begin{abstract}
Formaldehyde is a carcinogenic compound that was employed as fungicide in the past. Despite its disuse, some foods such as mushrooms naturally produce formaldehyde, showing the importance of its determination. In this work, a mechanized flow system based on solenoid valves is proposed for spectrophotometric formaldehyde determination in mushrooms. The analyte was extracted from fresh and dried mushrooms samples by steam distillation with deionized water in the presence of phosphoric acid. The determination was based on the reaction between formaldehyde and acetylacetone in presence of ammonium acetate (Hantzsch reaction), leading to the formation of 3,5-diacetyl-1,4-dihydrolutidine (DDL, $\lambda_{\max }=412 \mathrm{~nm}$ ). Linear response from 0.2 to $7.0 \mathrm{mg} \mathrm{L}^{-1}$ was achieved, with detection limit estimated at $0.02 \mathrm{mg} \mathrm{L}^{-1}$ (99.7\% confidence level). Coefficient of variation and sample throughput were $1.1 \%(\mathrm{n}=15)$ and $17 \mathrm{~h}^{-1}$, respectively. Per determination, $11 \mathrm{mg}$ of acetylacetone and $30 \mathrm{mg}$ of ammonium acetate were consumed, generating $4.2 \mathrm{~mL}$ of waste. The procedure was applied to formaldehyde determination in fresh and dried shiitake, and fresh shimeji, and the results agreed with those attained by reference method at the $95 \%$ confidence level.
\end{abstract} shimeji

Keywords: formaldehyde extraction, flow injection analysis, multicommutation, shiitake,

\section{Introduction}

Formaldehyde is a common carbonyl compound derived from combustion and oxidation of hydrocarbons ${ }^{1}$ employed as a fungicide, pesticide and disinfectant. ${ }^{2}$ The International Agency for Research on Cancer (IARC) ${ }^{3}$ has classified formaldehyde as carcinogenic to humans. The World Health Organization (WHO, 2002) ${ }^{4}$ has established a formaldehyde tolerable daily intake at $0.15 \mathrm{mg} \mathrm{kg}^{-1}$ body weight per day. Alternatively, US Environmental Protection Agency (EPA) ${ }^{5}$ establishes an acceptable daily intake at 0.2 $\mathrm{mg} \mathrm{kg}{ }^{-1}$ body weight per day for formaldehyde.

Some mushrooms contain naturally occurring formaldehyde, such as shiitake (Lentinula edodes) and shimeji (Pleurotus ostreatus). ${ }^{6}$ These genera of mushrooms may produce formaldehyde during their growth, even when this aldehyde is not used as air disinfectant in mushroom cultures. ${ }^{7}$ Formaldehyde could be naturally generated in mushrooms by enzymatic reactions, acid

*e-mail: munoz@ufu.br; sidgons@gmail.com hydrolyses or thermal degradation. The potential sources might contain the formaldehyde derived from breakdown of large molecules, including $\mathrm{N}-, \mathrm{O}-$ and S-methoxy compounds, lentinic acid or various sulfur compounds, for example 1,2,4-trithiolane, 1,2,4,5-tetrathiane and dimethyl disulfide. ${ }^{7}$ Previous works have reported formaldehyde content in shiitake mushroom in the range of $110-240 \mu \mathrm{g} \mathrm{g}^{-1}$.

Formaldehyde extraction in mushroom samples generally involves steam distillation ${ }^{7,8}$ or ultrasoundassisted extraction. ${ }^{9,10}$ Thus, the present amount of formaldehyde in food samples may be distinguished as free, bonded and total formaldehyde. Free formaldehyde is related to directly available formaldehyde in the sample, while bonded refers to larger molecules present in the matrix containing this aldehyde. Total formaldehyde is the sum of free and bonded amounts. ${ }^{7}$

Sample preparation is a critical step in the analysis of formaldehyde in food samples due to the high analyte reactivity, which may react with proteins, amino acids and other matrix components. To release the analyte from the sample matrix, steam distillation in acid medium is 
necessary. ${ }^{11,12}$ Thus, this extraction cannot quantify free and bound formaldehyde independently and a large quantity of sample and extraction solution are employed. ${ }^{7,12,13}$

Formaldehyde is commonly determined by spectrophotometry,,$^{14}$ fluorimetry, ${ }^{15}$ chemiluminescence ${ }^{16}$ or separation techniques. ${ }^{17}$ Procedures based on fluorimetric or spectrophotometric detection using acetylacetone (2,4-pentadione) for chemical derivatization have been commonly used. ${ }^{18}$ The acetylacetone method was developed by $\mathrm{Nash}^{19}$ and based on Hantzsch reaction. Formaldehyde reacts with acetylacetone in presence of ammonium acetate leading to the formation of 3,5-diacetyl-1,4-dihydrolutidine (DDL). This reaction is highly recommended for derivatization due to the selectivity, despite its low kinetic reaction rate. ${ }^{20}$

Flow injection analysis also increases the sampling throughput of methods based on slow reactions. Flow systems based on solenoid valves use individually controlled devices to design the manifold. ${ }^{21}$ This approach confers to flow system versatility with low sample and reagent consumptions, with satisfactory reproducibility. ${ }^{22}$

In this work, a multicommuted flow system with solenoid valves and spectrophotometric detection exploiting the formation of DDL was developed for determination of formaldehyde in mushrooms after steam distillation extraction. Sample preparation was optimized to obtain suitable conditions for quantitative analyte extraction.

\section{Experimental}

\section{Apparatus}

The flow system was designed with four three-way solenoid valves (N Research, West Caldwell, NJ, USA), polyethylene tubes (Ismatec, Germany, $1.0 \mathrm{~mm}$ ) and one confluence joint. A peristaltic pump (Minipuls TM 3, Gilson, Villiers Le Bel, France) equipped with eight channels and Tygon ${ }^{\circledR}$ tubes were used to pump the solutions through the system (in the pushing mode). The solenoid valves were controlled through an open-source electronic prototyping platform (Arduino ${ }^{\circledR}$ ) connected in a USB 2.0 port of a microcomputer (Intel Celeron $2.4 \mathrm{GHz}$, 256 MB RAM). The electric potential and current required to switch on the devices $(12 \mathrm{~V}, 100 \mathrm{~mA})$ were supplied by a lab-made electronic power drive based on a ULN2803 integrated circuit. Spectrophotometric measurements were carried out with a spectrophotometer (Femto 600 S, São Paulo, SP, Brazil) equipped with a glass flow cell (Hellma, Plainview, NY, USA) with $10 \mathrm{~mm}$ optical path and $80 \mu \mathrm{L}$ internal volume. The software provided by Femto was used for data acquisition.

\section{Reagents and solutions}

All solutions were prepared from analytical grade chemicals and distilled-deionized water $(18.2 \mathrm{M} \Omega \mathrm{cm}$, Milli-Q, Gehaka, Brazil). Formaldehyde standard stock solution $\left(0.03 \mathrm{~mol} \mathrm{~L}^{-1}\right)$ was prepared by diluting appropriate amounts of formaldehyde 37\% (Sigma-Aldrich, Germany) in water, and standardized by iodimetry. ${ }^{23}$ Reference solutions were daily prepared by proper dilutions of the stock. Reagent solution $0.4 \mathrm{~mol} \mathrm{~L}^{-1}$ acetylacetone (Sigma-Aldrich, Germany) in $1.4 \mathrm{~mol} \mathrm{~L}^{-1}$ ammonium acetate $(\mathrm{pH}=5.5)$ was daily prepared.

\section{Flow diagram and procedure}

The flow manifold for determination of formaldehyde in mushrooms is represented in Figure 1. The flow system was operated as described in Table 1, exploiting binary sampling approach. ${ }^{23}$ Sample or standard solutions (step 1) and reagent (step 2) were alternately inserted into the analytical path until 7 sampling cycles were completed. The sample zone was stopped for $60 \mathrm{~s}$ in the reaction coil (step 3), which was immersed in a thermostatic bath at $50{ }^{\circ} \mathrm{C}$. Sequentially, the sample zone was carried towards the detector and subsequently to the waste (step 4). All measurements were taken in triplicate. In step 5 , valve $\mathrm{V}_{4}$ was switched on for faster solutions replacement, thus avoiding contamination of the analytical path.

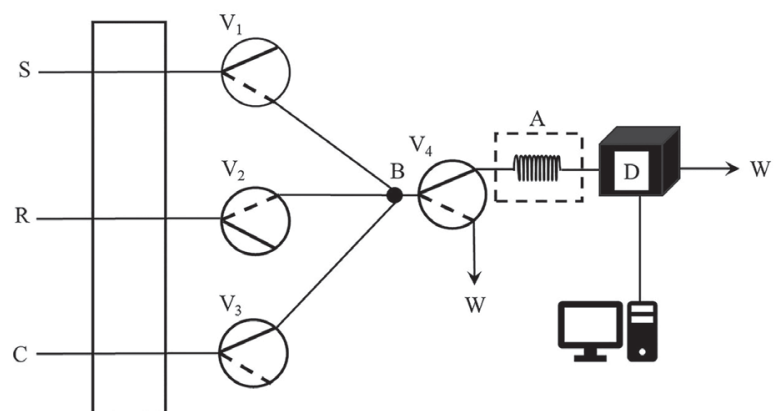

Figure 1. Flow diagram of the multicommuted system for formaldehyde determination. S: sample or reference solution; R: Nash reagent; C: carrier $\left(\mathrm{H}_{2} \mathrm{O}\right)$; P: peristaltic pump; $\mathrm{V}_{1^{-}}-\mathrm{V}_{4}$ : solenoid valves; $\mathrm{B}$ : confluence point; A: $200 \mathrm{~cm}$ mixing coil in thermostatic bath $\left(50{ }^{\circ} \mathrm{C}\right)$; D: detector and W: waste vessel.

\section{Formaldehyde extraction}

All mushrooms samples (fresh shiitake and shimeji, and dried shiitake) were purchased from local market. The samples were cut into strips and beat in a blender. The resulting sample was kept at $2-4{ }^{\circ} \mathrm{C}$ until analysis. For fresh shiitake or shimeji, $0.5 \mathrm{~g}$ was weight and transferred to a flask containing $25 \mathrm{~mL}$ of $\mathrm{H}_{3} \mathrm{PO}_{4}(1.2 \%$, v/v). For 
Table 1. Operational steps for the multicommuted flow system for spectrophotometric determination of formaldehyde in mushroom

\begin{tabular}{|c|c|c|c|c|c|c|}
\hline Step & Description & $\mathrm{V}_{1}$ & $\mathrm{~V}_{2}$ & $\mathrm{~V}_{3}$ & $\mathrm{~V}_{4}$ & time $/ \mathrm{s}$ \\
\hline 1 & sample injection $^{\mathrm{a}}$ & 1 & 0 & 0 & 1 & 4.0 \\
\hline 2 & reagent injection ${ }^{\mathrm{a}}$ & 0 & 1 & 0 & 1 & 1.4 \\
\hline 3 & stopped flow & 0 & 0 & 0 & 1 & 60 \\
\hline 4 & measurement and cleaning & 0 & 0 & 0 & 0 & 110 \\
\hline 5 & sample replacement & 1 & 0 & 0 & 1 & 10 \\
\hline
\end{tabular}

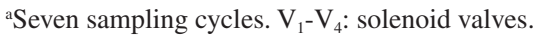

dried shiitake, $0.1 \mathrm{~g}$ was weight and transferred to a flask containing $60 \mathrm{~mL}$ of $\mathrm{H}_{3} \mathrm{PO}_{4}(0.5 \%$, v/v). The distillation was stopped after the flask becomes completely dry (approximately $60 \mathrm{~min}$ ).

Recovery tests were carried out by addition of known amounts of formaldehyde directly into the samples, and then treated as mentioned above.

\section{Results and Discussion}

\section{System optimization}

Under certain conditions, formaldehyde reacts with acetylacetone in the presence of ammonium acetate, forming a yellow product (3,5-diacetyl-1,4-dihydrolutidine) with absorption maximum at $412 \mathrm{~nm}$. This reaction is slow, requiring more than one hour to reach equilibrium. ${ }^{13}$ Therefore, the use of multicommuted flow analysis systems becomes an ideal alternative to decrease sample processing time and to carry out measurements at non-equilibrium condition in an accurate way. It can also reduce reagent consumption and waste generation. For the development of the procedure using multicommuted flow analysis with spectrophotometric measurements, several parameters were evaluated aiming at a compromised condition between sensitivity, reagent consumption and sample throughput. In this context, sample and reagent volumes, number of sampling cycles, stopped flow time, thermostatic bath temperature, acetylacetone and ammonium acetate concentrations and $\mathrm{pH}$ were evaluated. All measurements were carried out in triplicate and based on the peak height of the transient signals by monitoring the maximum absorption wavelength of DDL.

The univariate method was used for optimization. In all experiments a reaction coil of $200 \mathrm{~cm}$ was immersed in a thermostatic bath at $50{ }^{\circ} \mathrm{C}$, and the flow was stopped for $60 \mathrm{~s}$ prior detection. Additionally, the flow rate was kept at $1.7 \mathrm{~mL} \mathrm{~min}{ }^{-1}$. Binary sampling approach was exploited using seven cycles.

Sample and reagents volumes for formaldehyde determination were varied by altering the activation time of solenoid valves of the sample (Figure 2a) and of the reagent (Figure 2b). Higher activation times implied on higher volumes. The analytical signal increased up to $4.0 \mathrm{~s}$, followed by a decrease when higher volumes were employed (Figure 2a). The profile can be explained by the dilution of the reagent in the sample zone despite the lower dispersion of the sample. On the other hand, as demonstrated in Figure $2 b$, activation time for reagent valve higher than $1.4 \mathrm{~s}$ did not yield significant increase in the analytical signal, showing a tendency to decrease for $1.8 \mathrm{~s}$, due to the sample dilution. No improvement on analytical
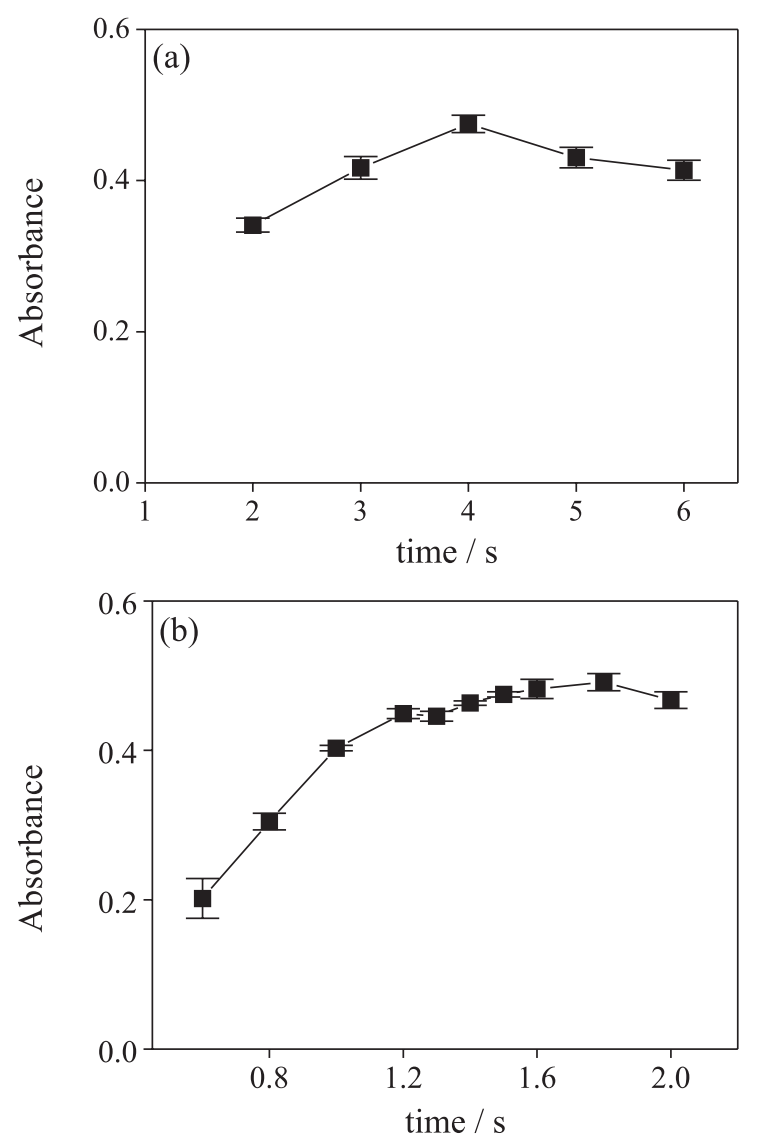

Figure 2. Effect of switching the time of analyte (a) and reagent (b) valve on the analytical signals. Reagents concentration: $1.95 \mathrm{~mol} \mathrm{~L}^{-1}$ ammonium acetate $(\mathrm{pH}=5.5)$ and $0.02 \mathrm{~mol} \mathrm{~L}^{-1}$ acetylacetone. Valves switching time: (a) reagent $1.2 \mathrm{~s}$ and (b) analyte $4.0 \mathrm{~s}$. Formaldehyde concentration: $5 \mathrm{mg} \mathrm{L}^{-1}$. 
signal was observed for times above $1.4 \mathrm{~s}$. Therefore, 4.0 and $1.4 \mathrm{~s}$ were selected for activation times for sample and reagent solenoid valves, respectively.

The effect of temperature was investigated within the range of $20-50{ }^{\circ} \mathrm{C}$ aiming at enhancing reaction rate and consequently, increasing sensitivity. Temperatures higher than $50{ }^{\circ} \mathrm{C}$ were not evaluated due to gas evolution caused by the decreasing gases solubility at higher temperatures. Higher temperatures increase the formation of DDL, giving better analytical signal. For this reason, the thermostatic bath temperature of $50{ }^{\circ} \mathrm{C}$ was maintained for further studies.

Concentrations of acetylacetone and ammonium acetate and $\mathrm{pH}$ were also studied and the effects on the analytical signal are shown in Figure 3. According to these results, $0.4 \mathrm{~mol} \mathrm{~L}^{-1}$ acetylacetone, $1.4 \mathrm{~mol} \mathrm{~L}^{-1}$ of ammonium acetate and $\mathrm{pH} 5.5$ provided better signal. The selected $\mathrm{pH}$ is close to that used in batch ${ }^{12}$ and flow-based ${ }^{21}$ spectrophotometric procedures. The selected conditions are summarized in Table 2.

\section{Analytical features}

A linear response was observed from 0.2 to $7.0 \mathrm{mg} \mathrm{L}^{-1}$ of formaldehyde, described by the equation $\mathrm{A}=(0.124 \pm 0.002) \mathrm{C}_{\text {Form. }}+(0.026 \pm 0.002), \mathrm{r}=0.999$, in which A represents analytical signal (absorbance) at the peak height and $\mathrm{C}_{\text {Form. }}$ the concentration of formaldehyde in $\mathrm{mg} \mathrm{L}^{-1}$. Transient signals for formaldehyde solutions are shown in Figure 4. The coefficient of variation and sampling throughput were estimated as $1.1 \%(\mathrm{n}=15)$ and 17 determinations $\mathrm{h}^{-1}$, respectively. The detection limit was estimated as $0.02 \mathrm{mg} \mathrm{L}^{-1}$ (99.7\% of confidence level), equivalent to 1 and $12 \mu \mathrm{g} \mathrm{g}^{-1}$, for fresh and dried mushroom, respectively. Per determination, $11 \mathrm{mg}$ of acetylacetone and $30 \mathrm{mg}$ of ammonium acetate were consumed, generating $4.2 \mathrm{~mL}$ of waste.

\section{Formaldehyde extraction}

Formaldehyde extraction from food samples requires steam distillation in acid medium for complete analyte release from the sample matrix. ${ }^{12}$ For formaldehyde determination in mushrooms, larger amount of sample and extraction solvent are usually employed. Sample mass and volume of extractor employed in these works may vary considerably across the different works and a more detailed study is necessary to establish better extraction conditions, specifically the relationship between sample mass and volume of extractor.

In this work, steam distillation method was employed for formaldehyde extraction using $\mathrm{H}_{3} \mathrm{PO}_{4}$ as extractor
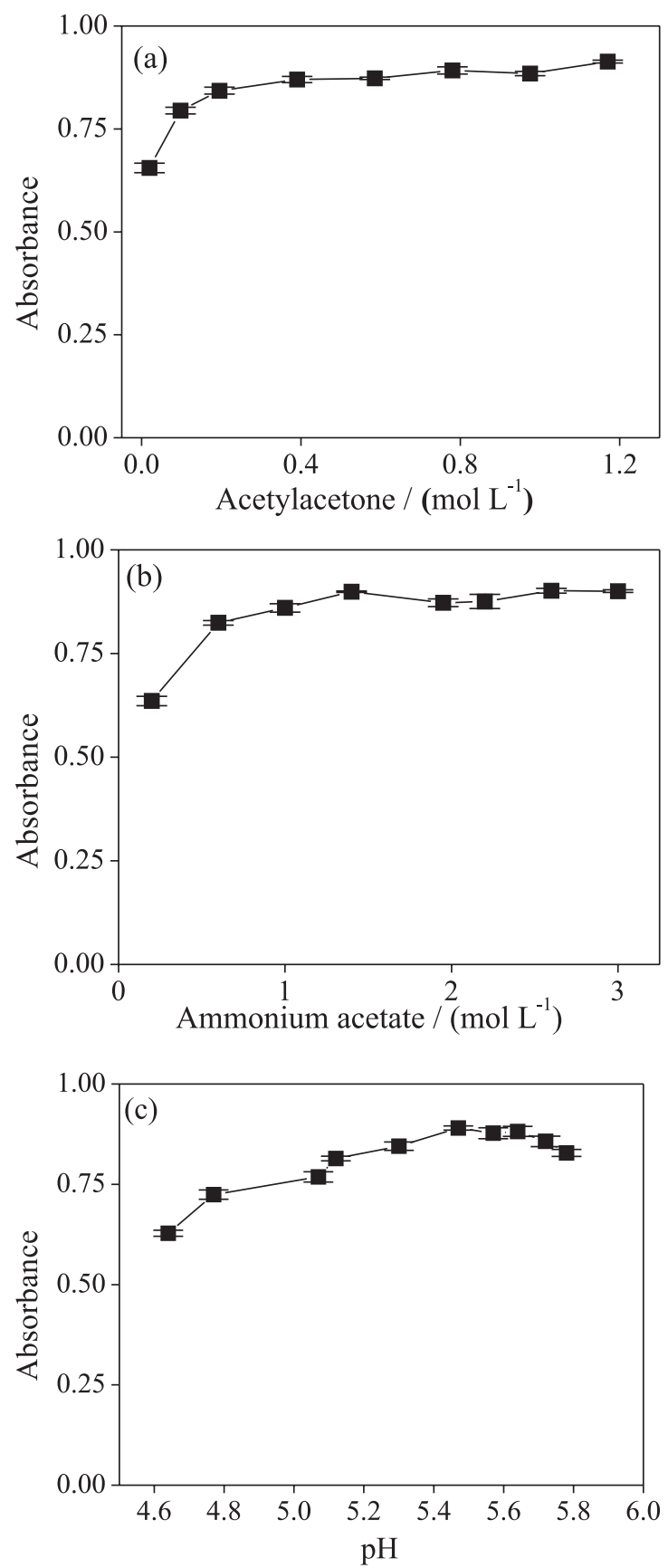

Figure 3. Effect of concentration of (a) acetylacetone; (b) ammonium acetate and (c) $\mathrm{pH}$ in the analytical signal. Reagent concentration: (a) $1.95 \mathrm{~mol} \mathrm{~L}^{-1}$ ammonium acetate $(\mathrm{pH}=5.5)$; (b) $0.4 \mathrm{~mol} \mathrm{~L}^{-1}$ acetylacetone and (c) $1.4 \mathrm{~mol} \mathrm{~L}^{-1}$ ammonium acetate and 0.4 acetylacetone $\mathrm{mol} \mathrm{L}^{-1}$. Formaldehyde concentration: $5 \mathrm{mg} \mathrm{L}^{-1}$. Reagent and analyte valves switching times were 4.0 and $1.4 \mathrm{~s}$, respectively.

solution. To determine adequate conditions for complete formaldehyde release in mushroom samples, the effect of sample mass and extractor volume $\left(\mathrm{H}_{2} \mathrm{O}\right)$ was investigated. All studies were performed employing $3.0 \mathrm{~mL}$ of phosphoric acid solution $(10 \% \mathrm{v} / \mathrm{v})$, as solvent extractor, and the distillation was stopped after the flask becomes completely dry. 
Table 2. Selected parameters of the flow-based procedure for formaldehyde determination in mushrooms

\begin{tabular}{|c|c|c|}
\hline Parameter & Evaluated range & Selected value \\
\hline Switching time V1 / s & $2.0-6.0$ & 4.0 \\
\hline Switching time V2 / s & $0.2-2.0$ & 1.4 \\
\hline Stopped flow / s & $30-150$ & 60 \\
\hline Acetylacetone / $\left(\mathrm{mol} \mathrm{L}^{-1}\right)$ & $0.1-0.6$ & 0.4 \\
\hline Ammonium acetate / $\left(\mathrm{mol} \mathrm{L}^{-1}\right)$ & $0.2-3.0$ & 1.4 \\
\hline $\mathrm{pH}$ & $4.7-5.8$ & 5.5 \\
\hline
\end{tabular}

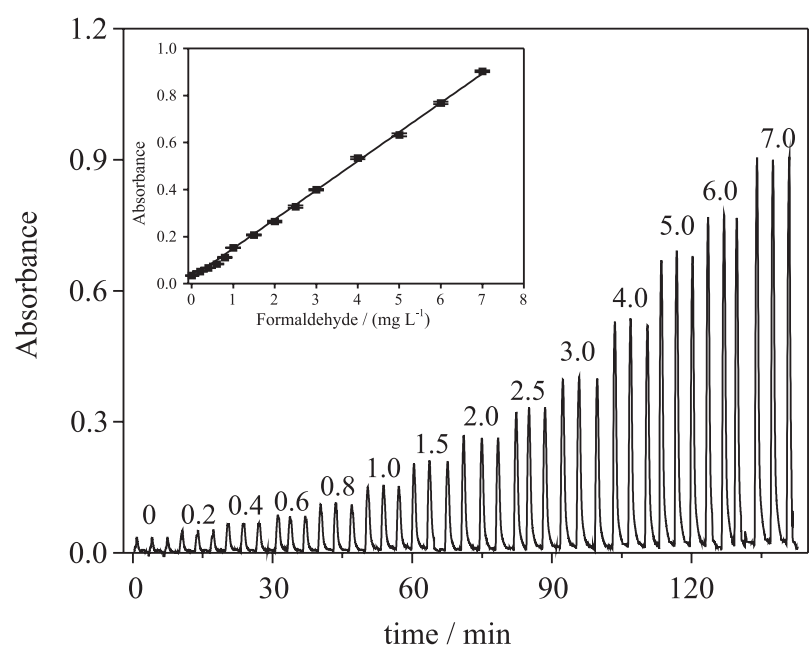

Figure 4. Transient signals for formaldehyde solutions. Numbers indicate concentrations in $\mathrm{mg} \mathrm{L}^{-1}$ and the curve inset shows the corresponding analytical curve. Experimental conditions are described in Table 2.

Initially, the effect of sample mass was evaluated keeping the extractor volume in $50 \mathrm{~mL}(3.0 \mathrm{~mL}$ phosphoric acid plus $47.0 \mathrm{~mL}$ deionized water). Two different sample amounts were evaluated, 0.5 and $1.5 \mathrm{~g}$ for fresh mushrooms, and 0.1 and $0.25 \mathrm{~g}$ for dried sample. According to Table 3, for fresh mushrooms, sample amount of $1.5 \mathrm{~g}$ showed lower formaldehyde amount. The lower extraction efficiency can be associated to insufficient extractor volume for complete formaldehyde removal. For dried sample, similar results

Table 3. Effect of sample mass for formaldehyde extraction in mushroom samples

\begin{tabular}{lcc}
\hline Sample & Mass / g & $\begin{array}{c}\text { Concentration / } \\
\left(\mu \mathrm{g} \mathrm{g}^{-1}\right)\end{array}$ \\
\hline Fresh shimeji & 0.50 & $16.1 \pm 1.1$ \\
Fresh shiitake & 1.50 & $9.2 \pm 0.6$ \\
& 0.50 & $34.6 \pm 1.2$ \\
Dried shiitake & 1.50 & $28.3 \pm 0.9$ \\
& 0.10 & $437 \pm 10$ \\
\hline
\end{tabular}

were obtained in both conditions. Therefore, the sample amount of 0.5 and $0.1 \mathrm{~g}$ were selected for fresh and dried mushroom, respectively.

For fresh mushrooms, similar results were obtained for $25 \mathrm{~mL}$ (3.0 mL phosphoric acid plus $22.0 \mathrm{~mL}$ deionized water) of extractor solution. However, as shown in Table 4, a larger amount of extractor solution was required for dried mushroom since the expected formaldehyde concentration in this sample is usually 15 -fold higher than in fresh samples. The highest formaldehyde concentration was obtained for extractor volume larger than $60 \mathrm{~mL}(3.0 \mathrm{~mL}$ phosphoric acid plus $57.0 \mathrm{~mL}$ deionized water), and this value was selected for further studies. In addition, the lowest extractor volume and sample amount results in decreased sample preparation time, improving sample throughput. In these conditions, the sample consumption of the proposed procedure was 40 -fold lower than those reported for formaldehyde determination in fresh shiitake samples. $^{?}$

Table 4. Effect of extractor volume for formaldehyde extraction in dried shiitake

\begin{tabular}{lcc}
\hline Sample & $\begin{array}{c}\text { Extractor volume / } \\
\mathrm{mL}\end{array}$ & $\begin{array}{c}\text { Concentration / } \\
\left(\mu \mathrm{g} \mathrm{g}^{-1}\right)\end{array}$ \\
\hline & 80 & $468 \pm 14$ \\
Dried Shiitake & 60 & $478 \pm 12$ \\
& 50 & $437 \pm 10$ \\
& 20 & $248 \pm 12$ \\
\hline
\end{tabular}

According to this proposed procedure for formaldehyde extraction, the detection limit values were equivalent to 1 and $12 \mu \mathrm{g} \mathrm{g}^{-1}$ for fresh and dried mushrooms, respectively.

\section{Sample analysis}

The proposed procedure for formaldehyde determination was applied to the analysis of three mushrooms samples (fresh and dried shiitake and fresh shimeji), and the results are shown in Table 5. The results were compared with those obtained by spectrophotometric batch procedure. ${ }^{19}$ The results in Table 5 agreed at the $95 \%$ confidence level (paired $t$-test), with good correlation. For dried shiitake, high formaldehyde concentration was observed. Although this high concentration in mushroom, formaldehyde is more toxic only through inhalation and not for consumption. ${ }^{24}$ The samples were spiked (by addition of stock solution) with 25 and $50 \mu \mathrm{g}$ for fresh shimeji and shiitake and with 60 and $120 \mu \mathrm{g}$ for dried shiitake (Table 6) prior sample extraction. Recoveries between 86 and $112 \%$ were obtained. 
Table 5. Formaldehyde determination in mushrooms samples. Uncertainties and mean values are based on 3 analytical determinations

\begin{tabular}{lcc}
\hline \multirow{2}{*}{ Sample } & \multicolumn{2}{c}{ Formaldehyde concentrations $/\left(\mu \mathrm{g} \mathrm{g}^{-1}\right)$} \\
\cline { 2 - 3 } Fresh shimeji & Batch $^{19}$ & Proposed method \\
\hline Fresh shiitake & $29.7 \pm 1.2$ & $27.4 \pm 0.9$ \\
Dried shiitake & $30.2 \pm 0.8$ & $28.8 \pm 0.6$ \\
\hline
\end{tabular}

Table 6. Samples formaldehyde recovery for the batch procedure and the proposed method. Uncertainties and mean values are based on 3 analytical determinations

\begin{tabular}{lcc}
\hline \multirow{2}{*}{ Sample } & \multicolumn{2}{c}{ Recovery /\% } \\
\cline { 2 - 3 } Fresh shimeji $+25 \mu \mathrm{g}$ & $100.0 \pm 1.2$ & Proposed method \\
\hline Fresh shimeji $+50 \mu \mathrm{g}$ & $98.3 \pm 0.5$ & $88.6 \pm 0.6$ \\
Fresh shiitake $+25 \mu \mathrm{g}$ & $95.7 \pm 2.5$ & $93.8 \pm 0.8$ \\
Fresh shiitake $+50 \mu \mathrm{g}$ & $85.2 \pm 0.6$ & $90.6 \pm 0.8$ \\
Dried shiitake $+60 \mu \mathrm{g}$ & $86.1 \pm 0.9$ & $92.0 \pm 1.9$ \\
Dried shiitake $+120 \mu \mathrm{g}$ & $102.7 \pm 1.7$ & $114.0 \pm 2.4$ \\
\hline
\end{tabular}

\section{Conclusions}

The multicommuted spectrophotometric procedure proposed was successfully applied for formaldehyde determination in mushrooms samples after steam distillation extraction with phosphoric acid solution. Profitable analytical features were achieved, such as reduction of the sample mass employed for formaldehyde extraction and low residue generation. Formaldehyde concentrations of all analyzed samples with the proposed procedure agreed with the reference one, confirming the accuracy and viability of the proposed procedure. Additionally, satisfactory recoveries were achieved (between 86 and 112\%).

The proposed procedure is then a reliable, fast and precise alternative for formaldehyde determination in mushrooms, using minimum amounts of reagents and generating low waste volume.

\section{Acknowledgments}

The authors are grateful to the support from the National Council for Scientific and Technological Development (CNPq, process number 308174/2013-5) and Coordination for the Improvement of Higher Level Personnel (CAPES). Support from the Minas Gerais State Agency for Research and Development (FAPEMIG) is greatly appreciated.

\section{References}

1. World Health Organization (WHO); Formaldehyde, Environmental Health Criteria; WHO: Geneva, Switzerland, 1989.
2. Wang, S.; Cui, X. J.; Fang, G. Z.; Food Chem. 2007, 103, 1487.

3. International Agency for Research on Cancer (IARC), http:// monographs.iarc.fr/ENG/Monographs/vol100F/mono100F-29. pdf, accessed in September 2017.

4. World Health Organization (WHO); Formaldehyde; WHO: Geneva, Switzerland, 2002. Available at http://www.who.int/ ipcs/publications/cicad/en/cicad40.pdf, accessed in July 2017.

5. US Environmental Protection Agency (US EPA), https://archive. epa.gov/region5/teach/web/pdf/formaldehyde_summary.pdf, accessed in September 2017.

6. Royse, D. J.; Schisler, L. C.; Diehle, D. A.; Interdiscip. Sci. Rev. 1985, 10, 329.

7. Mason, D. J.; Sykes, M. D.; Panton, S. W.; Rippon, E. H.; Food Addit. Contam. 2004, 11, 1071.

8. Cui, X.; Fang, G.; Jiang, L.; Wang, S.; Anal. Chim. Acta 2007, 590, 253.

9. Liu, J. F.; Peng, J. F.; Jiang, G. B.; Talanta 2005, 65, 705.

10. He, L.; Yang, X.; Ren, M.; Kong, X.; Liu, Y.; Lin, W.; Chem. Commun. 2016, 52, 9582.

11. Zhu, Y.; Peng, Z.; Wang, M.; Wang, R.; Rui, L.; J. Food Compos. Anal. 2012, 28, 1.

12. Yeh, T.-S.; Lin, T.-C.; Chen, C.-C.; Wen, H.-M.; J. Food Drug Anal. 2013, 21, 190.

13. Cui, X.; Fang, G.; Jiang, L.; Wang, S.; Anal Chim. Acta 2007, 590, 253.

14. Nascimento, C. F.; Brasil, M. A. S.; Costa, S. P. F.; Pinto, P. C. A. G.; Saraiva, M. L. M. F. S.; Rocha, F. R. P.; Talanta 2015, 144, 1189.

15. Guirong, L.; Lijuan, H.; Anal. Methods 2014, 6, 426.

16. Akshath, U. S.; Selvakumar, S.; Thakur, M. S.; Anal. Methods 2012, 4, 699.

17. Wahed, P.; Razzaq, M. A.; Dharmapuri, S.; Corrales, M.; Food Chem. 2016, 202, 476.

18. Sousa, E. T.; Oliveira, F. S.; Alves, A. C.; Andrade, J. B.; J. Braz. Chem. Soc. 2009, 20, 259.

19. Nash, T.; Biochem. J. 1953, 55, 416.

20. Vairavamurthy, A.; Roberts, J. M.; Newman, L.; Atmos. Environ. 1992, 26, 1965.

21. Rocha, F. R. P.; Reis, B. F.; Zagatto, E. A. G.; Lima, J. L. C.; Lapa, R. A. S. L.; Santos, J. L. M.; Anal Chim. Acta 2002, 468, 119.

22. Muñoz, M. P.; de Villena Rueda, F. J. M.; Díez, L. M. P.; Analyst 1989, 114, 1469.

23. Reis, B. F.; Giné, M. F.; Zagatto, E. A. G.; Lima, J. L. C.; Lapa, R. A.; Anal. Chim. Acta 1994, 293, 129.

24. Claeys, W.; Vleminckx, C.; Dubois, A.; Huyghebaert, A.; Hofte, M.; Daenens, P.; Schiffers, B.; Food Addit. Contam. 2009, 26, 1265 .

Submitted: September 28, 2017

Published online: January 8, 2018 